\title{
Science Academies' Refresher Course in Plant Taxonomy and Ethnobotany
}

\author{
Organized by \\ Department of Botany, Yogi Vemana University \\ Kadapa, Andhra Pradesh, India. \\ January 18-31 2018 \\ Sponsored by \\ Indian Academy of Sciences, Bengaluru \\ Indian National Science Academy, New Delhi \\ The National Academy of Sciences, India, Allahabad
}

\begin{abstract}
A Refresher Course in 'Plant Taxonomy and Ethnobotany' will be held in the Department of Botany, Yogi Vemana University, Kadapa, from 18 to 31 January 2018 for the benefits of faculty involved in teaching undergraduate and postgraduate courses. Participants in this course will gain practical and theoretical experience in Plant Taxonomy and Ethnobotany designed by Dr. R R Rao, the Course Director, INSA Honorary Scientist, Bangalore.

Applicants are invited from teachers with experience in teaching undergraduate and post graduate courses in Botany and life sciences especially in Plant Taxonomy and Ethnobotany. The number of seats will be 35 . Selected participants will be provided with round-trip bus/train (III AC) fare by the shortest route and local hospitality during the course in addition to course material.
\end{abstract}

Interested applicants must submit their application ONLINE by clicking on the following link.

http://web-japps.ias.ac .in: 8080/Refreshcourse/RPPP. jsp

A copy of the application form signed by the applicant should also be sent by post to the Course Coordinator. The application form must also be signed and stamped by the Head of the applicant's institution stating that leave will be sanctioned if the applicant is selected for the Course. A recommendation Irttrt with scanned copies of the duly signed documents sent by Email will also be accepted. Applications may be sent to Dr. A Madhusudhana Reddy, Course Coordinator, Refresher Course in 'Plant Taxonomy and Ethnobotany', Department of Botany, Yogi Vemana University, Kadapa 516 003, Andhra Pradesh. Email: grassced@yahoo.com Phone: 994-977-9166.

Last date of the receipt of applications: 15 November 2017.

Selected participants will be informed by: 1 December 2017. 